a guide to further study and information. These lists are an up-to-date bibliography of the literature of oral pathology, and as such are a most valuable addition.

Without doubt this edition will enjoy as great or an even greater success than its predecessor.

S.R.

\section{ROYAL NORTHERN OPERATIVE SURGERY}

Edited by Sir Lancelot Barrington Ward. 2nd Edition. Pp. vii +638 , with 498 illustrations. London: H. K. Lewis. 1951. £4 ros.

The first edition of this well-known book appeared in 1939: since that time surgery has advanced rapidly, and in particular the specialities have become well defined; in this new edition many sections have been rewritten to incorporate new knowledge and in particular additional sections covering many special branches of surgery, such as thoracic and plastic work, have been added. Virtually all the standard operations of surgery are described in varying detail, and the book is lavishly illustrated with drawings and photographs.

In a book of such size and range it is difficult to select sections for special consideration, particularly as the reviewer will inevitably devote more attention to those chapters covering subjects in which he himself is interested. However, mention must be made of the sections dealing with operations on the colon, rectum and anus, as these are particularly lucid and instructive, and are illustrated with most helpful pictures. The orthopaedic chapters, also, are outstanding, and the clear descriptions of many procedures should be particularly useful to general surgeons who may sometimes be called upon to operate for such conditions as recurrent dislocation of the shoulder, etc. The new sections on neuro-surgical, thoracic and plastic operations give a good picture of the techniques and problems in these specialities which should be most useful in particular to postgraduate examination candidates, as many textbooks are regrettably uninformative on these subjects. The last of these three sections contains an especially useful account of basic plastic procedures, containing much information of help to all practising surgeons.

The value of this work lies in the fact that it describes one sound method for performing all the standard operations of surgery, and for this reason it will continue to be of great help to postgraduate students and to young surgeons called upon to undertake operations with which they are as yet unfamiliar. But it must be emphasized that the book is solely one of operative surgery, and that the indications for operation, quite deliberately, are given only scant attention, as are the pre- and post-operative treatment.
Covering a subject in which personal judgmen民 and prejudice play so important a part, criticism may easily be invidious. But it seems a pity tha in the chapter on hernia all the methods described. for the repair of an inguinal hernia (including ever: Gallie's operation!) state that the conjoint and? inguinal ligaments should be apposed, and that there is no description of a lattice type of repair믐 Further in performing a gastrostomy under loca anaesthesia, the catheter can nearly always bed inserted without delivering a portion of the stomach outside the abdomen and holding it there in clamps as shown in the illustrations. And need facial skin $\vec{b}$ be insulted with heavy toothed clamps as shown in the figure illustrating excision of carcinoma of the $\vec{\omega}$ cheek? However, such criticisms must not be taken to decry the overall quality of this book 0 which covers all branches of operative surgery in. an authoritative manner, and which contains muchiv practical information of particular value to post $-\infty$ graduates and young practising surgeons.

\section{MEDICAL DISORDERS OF THE LOCOMOTORN SYSTEM, INCLUDING RHEUMATIC DISEASES}

By ERnest Fletcher, M.A., M.D., M.R.C.P 2nd Edition. Pp. xii +884 , with 377 illustra-T tions, 6 in colour. Edinburgh: E. \& S. Living $\frac{\mathbb{O}}{O}$ stone. I951. 60s.

The second edition of this important and value able textbook is to be welcomed. Progress in rheumatic diseases has been so rapid that it appearse only four years after the first, with the addition a long appendix on the pituitary-adrenal system and new sections from six contributors: Professors S. L. Baker writes a masterly chapter on the Physiology and Pathology of Bone, Professor C. Rimington writes on Synovial Mucin, and Dro H. J. Gibson, Dr. J. Barrie Murray, Dr. G. D. Kersley and Dr. A. P. Fletcher write respectivelyö on Laboratory Findings, Psychiatric Aspects,, Hydrotherapy and Pain. To name these additions? alone is to convey some idea of the scope of the book.

To single out points for adverse criticism is carping, but so authoritative a work should refero to the value of the $Q T$ interval in the diagnosis of $\mathrm{B}$. cardiac involvement in acute rheumatism ando should mention that salicylates and cardiac failure may mask the rise in E.S.R. (on p. 226 we read that the only exception to the rule that the E.S.R is raised in acute rheumatism is when chorea is the only manifestation). The neuropathic joint of diabetes is not mentioned. The review of then pituitary-adrenal system is remarkably completes but it should be emphasized that cortisone itself retards wound healing (p. 824). However, theses are minor flaws in a very complete and valuable book. 